\title{
Introduction to "Social Networking, Management Responsibilities, and Employee Rights: The Evolving Role of Social Networking in Employment Decisions"
}

\author{
Victor G. Devinatz ${ }^{1}$
}

Published online: 10 September 2015

(C) Springer Science+Business Media New York 2015

In the age of the Internet, social networking sites (SNS) have become ubiquitous. Popular SNS include Facebook, LinkedIn, Twitter, Instagram, and Pinterest, among others. New SNS are constantly springing up with once trendy SNS, such as Friendster, being replaced by newer SNS. The time that people spend on SNS is not insignificant. For example, in January 2013, one study reported that for Americans, ranging in age from 18 to 64 years old, who utilize social networks their time spent engaging in such activities, averaged out to $3.2 \mathrm{~h}$ per day. If those responding to the survey who stated that they did not use social networks are included, the average amount of time falls to $2 \mathrm{~h}$ a day in which Americans are social networking from one or more of their electronic devices which include computers, tablets and mobile phones. Younger Americans (18 to 34 years old) spend the most time of all age groups social networking at an average of $3.8 \mathrm{~h}$ daily. Additionally, females who utilize SNS spend approximately $40 \%$ more time on them than their male counterparts, averaging $3.6 \mathrm{~h}$ per day compared to $2.6 \mathrm{~h}$ per day.

In this well-written, interesting and timely essay, Dr. Steven L. Thomas, a Professor of Management at Missouri State University; Dr. Philip Rothschild, Director of Entertainment Management at Missouri State University, and Ms. Caroline Donegan, an employee benefits consultant with the global insurance brokerage firm, Lockton Companies, discuss the use of SNS by managers in employment situations. Because of the large amount of personal and behavioral information that can be obtained as well as being relatively easy and inexpensive to monitor, managers have been utilizing SNS in both the selection process and in determining whether employees are engaging in "potentially detrimental employee activities." While the authors acknowledge that government regulations typically lag the extant technology and point out that there is scant research concerning managerial use of SNS in the workplace, they do an excellent job of discussing the legal, ethical, and practical issues of engaging in such

Victor G. Devinatz

vgdevin@ilstu.edu

1 Department of Management \& Quantitative Methods, Illinois State University, Normal, IL 61790-5580, USA 
managerial behavior while providing guidelines for managers who do choose to participate in such practices.

I welcome employment relations scholars from around the globe to contribute future essays analyzing any employment-related topic from a wide variety of theoretical perspectives. Moreover, if any of the journal's readers would like to respond to particular essays or articles published in the "Perspectives" Section, please do not hesitate to contact me with your proposal. I welcome both practitioner-based and scholarly-based articles. I hope that you enjoy this essay and find it most illuminating. 